\title{
Fibrinogen Has a Rapid Turnover in the Healthy Newborn Lamb
}

\author{
M. ANDREW, L. MITCHELL, L. R. BERRY, B. SCHMIDT, AND M. W. C. HATTON \\ Departments of Pediatrics and Pathology, McMaster University Medical Centre, Hamilton, Ontario, Canada
}

\begin{abstract}
The half-lives for coagulation factors in the healthy newborn infant are not known and may be different than for the adult. We measured the half-life for fetal sheep fibrinogen and compared it to the half-life of adult sheep fibrinogen. Fibrinogen was purified from adult and fetal sheep plasma and radiolabeled with either ${ }^{125} I$ or ${ }^{131} I$. The half-lives for these fibrinogens were determined in the adult sheep and newborn lamb. In addition, the fetal and adult sheep fibrinogens were compared by reptilase time, thrombin clotting time, sialic acid content, and the behavior of the $\mathrm{N}$-glycans derived from these fibrinogens on the immobilized lectin, Sepharose-concanavalin A. Finally, the in vivo response of coinjected radiolabeled fibrinogens to increasing doses of infused thrombin was determined. The fetal sheep fibrinogen differed from the adult as indicated by a prolonged reptilase time and an increased sialic acid content (fetal: 10-11 residues/340 Kd versus adult: 8-9 residues $/ 340 \mathrm{Kd}$ ). The latter was also reflected in differing chromotographic profiles for the $\mathrm{N}$-glycans on Sepharoseconcanavalin A. The half-lives for both the adult and fetal fibrinogen were significantly more rapid in the newborn lamb (fetal: $47 \pm 2.0 \mathrm{~h}$; adult: $46 \pm 2.4 \mathrm{~h}$, mean \pm SEM) than in the adult (fetal: $116 \pm 6.5 \mathrm{~h}$; adult: $121 \pm 6.9 \mathrm{~h}$ ). Finally, the adult and fetal sheep fibrinogen responded to thrombin in an identical fashion in the intact animal. In summary, both adult and fetal fibrinogen have faster halflives in the lamb compared to the adult, despite a higher sialic acid content for the fetal fibrinogen. We speculate that the more rapid turnover of coagulation proteins in the newborn may be of significance when planning replacement therapy for congenital or acquired coagulopathies. (Pediatr Res 23: 249-252, 1988)
\end{abstract}

There is a growing appreciation that the neonatal coagulation system has unique features compared to the adult. For example, the levels of the coagulation factors vary with gestational and postnatal age, and the ability of the newborn coagulation system to generate thrombin and inhibit thrombin is impaired compared to the adult $(1,2)$. However, there is little information available on the comparison of the structure and pharmacokinetics of components of the coagulation system in the newborn with the adult. The most extensive information exists for fibrinogen which is thought to exist in a fetal form with an increased sialic acid content in the newborn infant (3-6). There is no information on the pharmacokinetics of fibrinogen in the healthy infant or on

Received June 22, 1987; accepted October 27, 1987.

Reprint requests Dr. M. Andrew, Department of Pediatrics, McMaster University Health Sciences Centre, Room HSC-3N27, 1200 Main Street, Hamilton, Ontario L8N 3Z5, Canada.

Supported by Grant NA7595 from the Medical Research Council of Canada M.A. is a Scholar of the Canadian Heart Foundation and M.W.C.H. is a Research Associate of the Heart and Stroke Foundation of Ontario. the response of the "fetal" fibrinogen to thrombin in vivo. Many of these questions can only be asked ethically in an animal model of newborn coagulation. We have used the sheep model to investigate the clearance and response to thrombin of "fetal" and adult fibrinogen. Our results show that fibrinogen, whether adult or fetal, has a faster turnover in the newborn compared to the adult and that both adult and fetal fibrinogen have a similar response in vivo to thrombin.

\section{MATERIALS AND METHODS}

Animal model. Plasma for purification of fibrinogen was obtained from adult sheep and from fetal lambs at approximately 100 days gestation with term being 147 days gestation. To obtain the fetal plasma, the pregnant ewe was given an epidural anesthetic supplemented with sedative doses of sodium pentobarbital by continuous intravenous infusion. The fetal lamb was partially delivered in a breech position through a uterine incision. Silastic catheters were placed in the fetal lamb's femoral artery and the fetal blood obtained.

Fibrinogen purification. Blood for fibrinogen purification was collected into polypropylene tubes containing $3.8 \%$ sodium citrate and EACA. A fraction of the blood obtained was centrifuged at $3000 \times g$ for $20 \mathrm{~min}$ and multiple aliquots of the plasma sample frozen at $-70^{\circ} \mathrm{C}$ for future coagulation assay. The remaining plasma was used for fibrinogen purification according to the method of Straughn and Wagner (7). In brief, the fibrinogen was prepared by absorbing plasma with aluminum gel followed by three precipitation steps with $\beta$-alanine. The final precipitate was resuspended in a citrate saline solution and frozen. Purified fetal fibrinogen was labeled with ${ }^{125} \mathrm{I}$ and adult fibrinogen with ${ }^{131}$ I using the iodine monochloride technique (8). The final fibrinogen solution had greater than $95 \%$ clottable protein content, showed the expected three bands on reduced sodium dodecyl sulfate-polyacrylamide gel electrophoresis, and after iodination more than $95 \%$ of the radioactivity was clottable with thrombin. In addition, human albumin (Connaught Laboratories, Toronto, Canada) was labeled with ${ }^{125} \mathrm{I}$ for kinetic studies, either in separate animals or in animals receiving ${ }^{131}$ Ilabeled fibrinogen.

Pharmacokinetic studies. The half-lives of the labeled fetal and adult fibrinogens and albumin were determined in the healthy newborn lamb during the 1st wk of life and in the healthy adult sheep. The adult sheep received $100 \mu \mathrm{Ci}$ of ${ }^{125} \mathrm{I}$-labeled fetal fibrinogen, $100 \mu \mathrm{Ci}$ of ${ }^{131}$ I-labeled adult fibrinogen, and/or 100 $\mu \mathrm{Ci}$ of ${ }^{125} \mathrm{I}$-labeled albumin, whereas the newborn lambs received $20 \mu \mathrm{Ci}$ of ${ }^{125} \mathrm{I}$-labeled fetal fibrinogen, $20 \mu \mathrm{Ci}{ }^{131} \mathrm{I}$-labeled adult fibrinogen, or $20 \mu \mathrm{Ci}$ of ${ }^{125} \mathrm{I}$-albumin. Baseline and subsequent blood samples $(2 \mathrm{ml})$ were drawn in heparinized syringes for measurement of fibrinogen (9), hematocrit, total protein (refractometer) and ${ }^{125} \mathrm{I}$-fibrinogen, ${ }^{131} \mathrm{I}$-fibrinogen, and/or ${ }^{125} \mathrm{I}$-albumin. In each case the whole blood samples were spun at $3500 \mathrm{rpm}$ for $15 \mathrm{~min}$ and $1-\mathrm{ml}$ plasma samples frozen for measurement of the radioactivity in a well-type $\gamma$-scintillation counter that allowed 
for correction if both ${ }^{125} I$ and ${ }^{131} I$ were used. Less than $1 \%$ of total counts were not precipitated with absolute ethanol, which indicates that more than $99 \%$ of the label was protein bound.

Thrombin infusion experiments. In these experiments both ${ }^{125} \mathrm{I}$-fetal fibrinogen and ${ }^{131} \mathrm{I}$-adult fibrinogen were injected into healthy adult sheep $(n=3)$ at least $24 \mathrm{~h}$ before study. On the day of study, two catheters were placed in the jugular veins. Exogenous bovine thrombin was infused into the right jugular vein at increasing doses $(0.1-1.2 \mathrm{U} / \mathrm{kg} / \mathrm{min})$. Blood samples were obtained as described above from the left jugular vein over the subsequent 2-h time period.

Evidence for a "fetal" fibrinogen. To confirm the presence of a "fetal" fibrinogen in the fetal lamb, both a $2-U$ thrombin clotting time, performed with and without calcium, and a reptilase time were performed in both fetal lamb plasma samples and adult sheep plasma samples. Sialic acid analyses of the purified fetal and adult fibrinogens were performed in duplicate using mild acid hydrolysis followed by the periodate oxidation-thiobarbituric acid method of Aminoff (10) using $\mathrm{N}$-acetyl neuraminic acid (Sigma Chemical Co., St. Louis, MO) as a standard. N-glycans were produced from fibrinogen by hydrazinolysis as described by Fukuda et al. (11) except that the glycans were desalted after cleavage and rotary evaporation on Biogel P-2 instead of Sephadex G-25. Chromatography of the isolated N-glycans on Sepharose-concanavalin A was carried out as previously described (12). Sialic acid analysis of the separated, concentrated fractions was performed. The final calculations of sialic acid content per molecule assumed a mol. wt. of $340 \mathrm{Kd}$ and an $\mathrm{E}^{1 \%}$ value of 15.5 (13)

Statistical analysis. Results are reported as means \pm SEM. The half-life of the fibrinogen was calculated using linear regression in the $\beta$-portion of the curve. Comparisons between the adult and newborn plasmas were performed with Student's unpaired $t$ test and a $p<0.05$ was considered significant. For multiple comparisons the Bonferroni correction was used and $p<0.01$ was considered significant.

\section{RESULTS}

Evidence for a fetal fibrinogen. Because the newborn lamb has a lower fibrinogen concentration than the adult sheep, the adult plasma was diluted in saline to a similar fibrinogen concentration as in the lamb. The fetal plasma showed a significantly prolonged reptilase time compared to the adult sheep plasma and a similar trend for the thrombin clotting time in the absence but not in the presence of $\mathrm{Ca}^{++}$(Table 1). Analysis of the sialic acid content showed that fetal fibrinogen samples contained considerably more sialic acid $(10.4,10.5$ residues/molecule) than adult fibrinogen $(8.8,8.8$ residues/molecule) (Table 2). Furthermore, the isolated $\mathrm{N}$-glycan fraction from fetal fibrinogen largely passed through Sepharose-concanavalin A (60\%) whereas less than $10 \%$ of glycans from adult fibrinogen passed through the lectin column. This confirmed the increased sialic acid content of the fetal fibrinogen and indicated that the majority of glycans on adult fibrinogen was biantennary whereas most fetal glycans were more branched (12).

Turnover studies. The pharmacokinetic curves for both fetal and adult fibrinogen were markedly different in the newborn lamb compared to the adult sheep (Figs. 1 and 2). The half-lives for both fetal and adult fibrinogen were significantly shorter in the newborn lamb compared to the adult sheep ( $40 \%$ of the adult value) (Table 3 ). The half-life of ${ }^{125}$ I-albumin in the lamb was $67 \%$ of the value in the adult sheep (Table 3 ).

Response to thrombin infusion. Figure 3 shows the response of the fetal and adult fibrinogen to an infusion of thrombin (the same thrombin used for the thrombin clotting times). At a dose of $1 \mathrm{U} / \mathrm{kg} / \mathrm{min}$ of thrombin, both the adult and fetal fibrinogen showed an increased consumption that was comparable for both fibrinogens.
Table 1. Coagulation tests (mean $\pm S E M$ )

\begin{tabular}{lcc}
\hline \multicolumn{1}{c}{ Test } & Fetus & Diluted adult sheep \\
\hline$n$ & 5 & 5 \\
Fibrinogen (g/liter) & $1.3 \pm 0.15$ & 1.3 \\
TCT $^{*}$ with $\mathrm{Ca}^{++}$ & $20.4 \pm 0.53 \dagger$ & $23.3 \pm 0.21$ \\
TCT without $\mathrm{Ca}^{++}$ & $54 \pm 7.5$ & $44 \pm 0.8$ \\
Reptilase (s) & $29 \pm 1.8 \dagger$ & $19 \pm 0.7$ \\
\hline
\end{tabular}

* Thrombin clotting time.

$\dagger$ A significant difference between the fetus and adult sheep of $<0.01$.

Table 2. Sialic acid content of fetal and adult sheep fibrinogen

\begin{tabular}{|c|c|c|}
\hline & $\begin{array}{c}\text { Fetal } \\
\text { fibrinogen }\end{array}$ & $\begin{array}{c}\text { Adult } \\
\text { fibrinogen }\end{array}$ \\
\hline
\end{tabular}

Sialic acid content (residue/mol- $\quad 10.4,10.5 \quad 8.7,8.8$

ecule)

$\%$ Distribution of $\mathrm{N}$-glycans on

Sepharose-concanavalin $\mathrm{A}^{*}$

\begin{tabular}{lrr} 
Unbound fraction & $61 \%$ & $8 \%$ \\
Bound fraction & $39 \%$ & $92 \%$ \\
\hline
\end{tabular}

${ }^{*}$ Determined from the sialic acid content of the N-glycans samples after chromotography on Sepharose-concanavalin A.

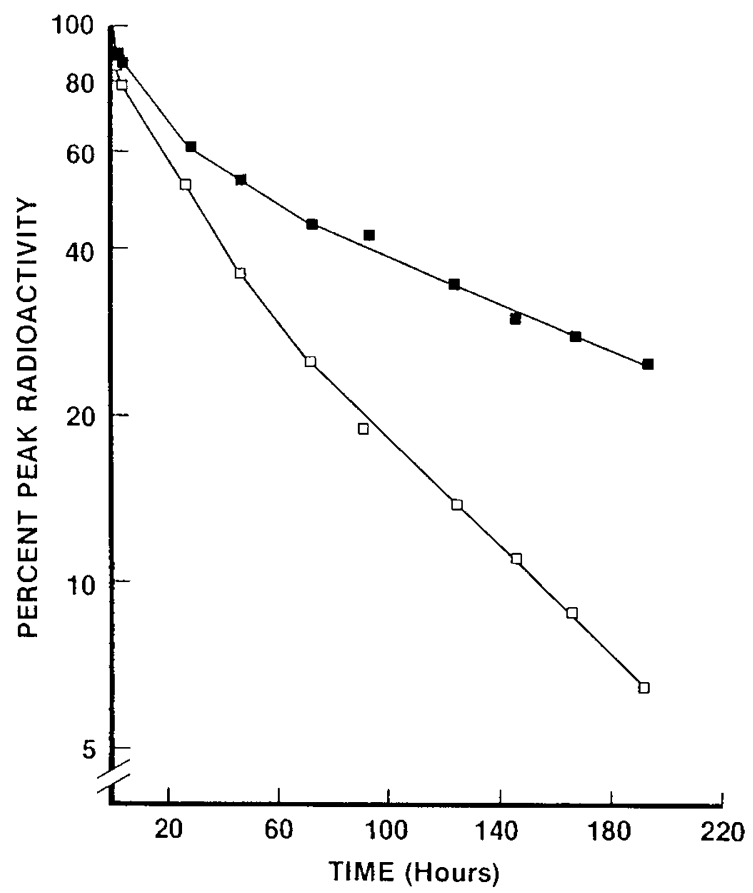

Fig. 1. The plasma survival curves of radiolabeled fetal lamb fibrinogen in the adult sheep ( $\mathbf{\square}, n=5)$ and newborn lamb $(\square, n=5)$. The fetal fibrinogen had a consistently faster turnover in the lamb compared to the sheep. The values are all expressed as the mean with all SEM less than $5 \%$.

\section{DISCUSSION}

The hemostatic system in the newborn infant has unique features when compared to the hemostatic system in the adult. One aspect of interest is the evidence for "fetal" forms of coagulation factors $(3-5,14-16)$ and their influence on the turnover of the coagulation protein in physiologic and pathophysiologic states. Because these studies would be generally considered unethical in the healthy human infant, they necessitate the use of an animal model. The fetal sheep was chosen for our study because the fetal sheep has been described as one model for the newborn coagulation system (17) and the lamb fibrinogen may 


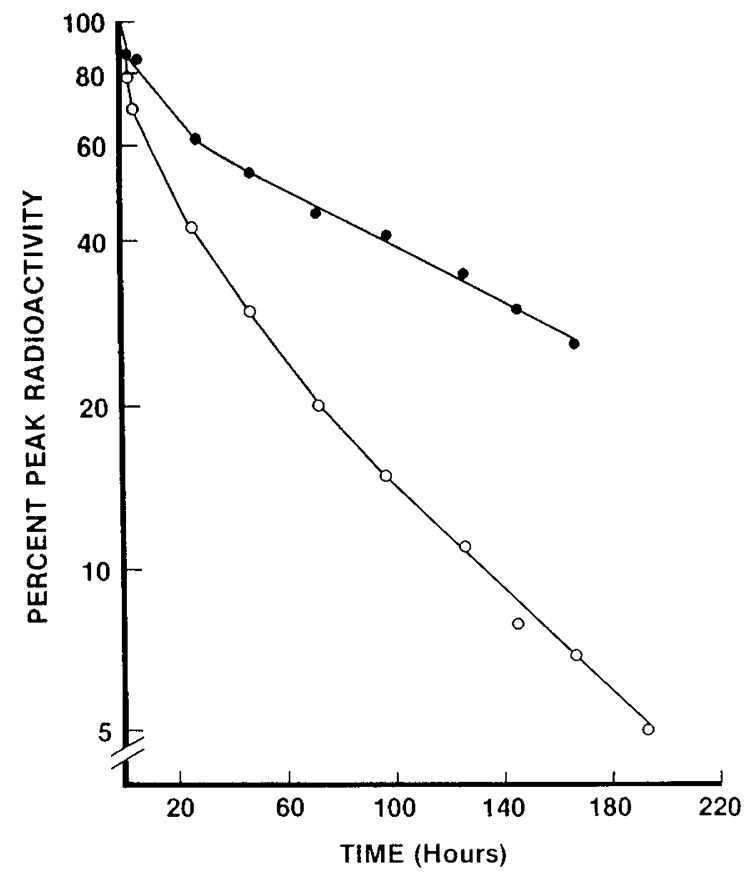

Fig. 2. The plasma survival curves of radiolabeled adult sheep fibrinogen in the adult sheep $(\bullet, n=7)$ and newborn lamb $(O, n=10)$. The adult fibrinogen had a consistently faster turnover in the lamb compared to the sheep. The values are expressed as the mean with all SEM less than $5 \%$.

Table 3. Apparent plasma half-lives of albumin and fibrinogen measured in newborn lamb and adult sheep*

\begin{tabular}{lcl}
\hline & Newborn $(\mathrm{h})$ & \multicolumn{1}{c}{ Adult $(\mathrm{h})$} \\
\hline${ }^{125}$ I-albumin & $144 \pm 23.4(4) \dagger$ & $214 \pm 17.8(5)$ \\
${ }^{125}$ I-fetal sheep fibrinogen & $47 \pm 2.0(5) \dagger$ & $116 \pm 6.5(5)$ \\
${ }^{131}$ I-adult sheep fibrinogen & $46 \pm 2.4(10) \dagger$ & $121 \pm 6.9(7)$ \\
\hline
\end{tabular}

$*$ Mean $\pm \operatorname{SEM}(n)$ where $n$ is the sample number.

$\dagger$ Statistical difference between the newborn and adult of $p<0.01$.

exist in a "fetal" form (18). Herein we show that sheep fibrinogen, whether fetal or adult, has a more rapid clearance in the healthy newborn lamb compared to the adult sheep. In addition, both the fetal and adult sheep fibrinogen respond in a similar fashion in vivo to a challenge with thrombin even though carbohydrate analyses revealed significant differences between the fetal and adult fibrinogen in sialic acid content and in the degree of branching of the N-glycans. Thus, the increased sialic acid content likely contributed to the in vitro demonstration of a dysfibrinogenemia in the lamb but did not contribute to the more rapid clearance of fibrinogen in the lamb.

We chose to study the clearance of fibrinogen because of its importance in blood clotting and because of the evidence for a "fetal" form of fibrinogen in the human infant. An increased sialic acid content is one of the main differences between human newborn and adult fibrinogen and is responsible for the delayed polymerization observed for the human fetal fibrinogen ex vivo (3-5). We were able to demonstrate similar abnormalities in fetal sheep fibrinogen compared to the human infant. Conceivably the presence of an increased sialic acid content and an altered $\mathrm{N}$-glycans branching profile in the fetal sheep fibrinogen molecule could result in a different response to thrombin in vivo as well as in vitro. We tested this hypothesis by directly infusing thrombin into the adult sheep containing both ${ }^{125} \mathrm{I}$-fetal and ${ }^{131} \mathrm{I}$ adult fibrinogens and demonstrated their similar response to thrombin. This observation indicates that the different carbohydrates carried by these fibrinogens are unlikely to influence the role of fibrinogen during intravascular coagulation. This conclu- sion agrees with the reports of Nishibe and Takahashi (19) and Gilman et al. (20) who found that neither deglycosylation nor the inhibition of glycosylation during biosynthesis changed the coagulant properties of fibrinogen. The physiologic reason for the increased sialic acid content of fetal sheep fibrinogen is not obvious. Other fetal proteins such as human fetal fibronectin (21) and human placental fibronectins (22) also contain a higher carbohydrate content than in the adult plasma. For fibronectin, as the carbohydrate content increases, the binding between fibronectin and collagen decreases. Whether the high sialic acid of fetal sheep fibrinogen alters functional properties in vivo is unknown.

Information on pharmacokinetics of coagulation factors in the healthy human full-term or premature infant is sparse and largely confined to the sick infant. Premature human infants with varying degrees of the respiratory distress syndrome show shortened ${ }^{125}$ I-fibrinogen survivals (half-life of 2.8 to 2.1 days) compared to healthy adults $(4.5$ days $)(23,24)$. One cannot be sure if these shortened fibrinogen survivals reflect a physiologic phenomena or a disease process. Indeed, antithrombin III survivals are reported to be shorter in reasonably healthy infants requiring an exchange transfusion for hyperbilirubinemia compared to the adult (25). In addition, small animals show a faster turnover of proteins in general compared to large animals, likely due to an increased basal metabolic rate. The shorter half-life for albumin in the newborn lamb compared to the adult sheep is compatible with this observation. The shorter half-life for at least one coagulation factor, fibrinogen, in a healthy newborn animal compared to the adult is likely in large part to be due to an increased metabolic rate. The similar rates of clearance observed for either fibrinogen in the lamb or the adult sheep (Figs. 2 and 3) indicate that, probably, differences in sialic acid content and the branched nature of the $\mathrm{N}$-glycans do not contribute toward the catabolism of fibrinogen. A similar conclusion was made by Barsigian et al. (26) who calculated similar half-lives for rabbit native fibrinogen and aglycofibrinogen in rabbits. Also, the early work of Wong et al. (27) demonstrated that plasma clearance of transferrin in rabbits was independent of any preceding desialylation in vivo. If other coagulation factors have a faster clearance in the newborn compared to the adult this information may have clinical relevance in the treatment of inherited disorders in the infant.

Acknowledgments. The authors acknowledge the secretarial assistance of Mrs. Janice Butera and Mrs. R. Phillis. In addition

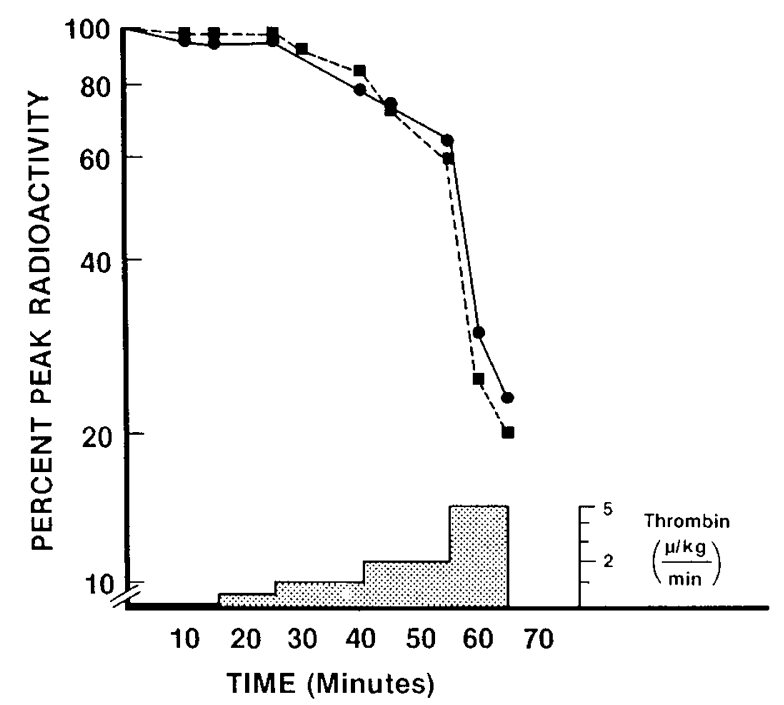

Fig. 3. The response of ${ }^{131}$ I-labeled adult fibrinogen $(\mathbb{\square})$ and ${ }^{125} \mathrm{X}$ labeled fetal fibrinogen ( $(\bullet)$ to an infusion of increasing doses of thrombin in the adult sheep. Both fibrinogens responded to the infused thrombin in a similar fashion. 
we also acknowledge the technical skills of Dr. M. Smith and A. Marianski.

\section{REFERENCES}

1. Andrew M, Paes B, Milner R, Johnston M, Mitchell L, Tollefsen DM, Powers P 1987 Development of the coagulation system in the fullterm infant. Blood 70:165-172

2. Schmidt B, Ofosu FA, Andrew M 1987 Inhibition of thrombin generation in vitro requires less heparin in the newborn than in the adult. Clin Invest Med 9(suppl):A78(abstr)

3. Galanakis DK, Mosesson MW 1976 Evaluation of the role of in vivo proteolysis (fibrinogenolysis) in prolonging the thrombin time of human umbilical cord fibrinogen. Blood 48:109-118

4. Hamulyak K, Nieuwenhuizen W, Devillee PP, Hemker HC 1983 Reevaluation of some properties of fibrinogen purified from cord blood of normal newborns. Thromb Res 32:301-320

5. Gralnick HR, Gilvelber H, Abrams E 1978 Dysfibrinogenemia associated with hepatoma. Increased carbohydrate content of the fibrinogen molecule. $\mathrm{N}$ Engl J Med 299:221-226

6. Witt I, Müller H, Künzer W 1969 Evidence for the existence of foetal fibrinogen. Thromb Diath 22:101-109

7. Straughn W III, Wagner RH 1966 A simple method for preparing fibrinogen Thromb Diath Haemorrh 16:198-206

8. Ikeno LC, Bowen BM, Der M 1981 Commercial production of ${ }^{125}$ I-fibrinogen for injection. J Radioanal Chem 65:179-188

9. Claus A 1957 Gerinnungsphysiologische Schnellmethode zur Bestimmung des Fibrinogens. Acta Haematol 17:237-246

10. Aminoff $\mathrm{D} 1961$ Methods for the quantitative estimation of $\mathrm{N}$-acetyl-neuraminic acid and their application to hydrolysates of sialomucoids. Biochem $\mathrm{J}$ $81: 384-392$

11. Fukuda M, Kondo T, Osawa T 1976 Studies of the hydrazinolysis of glycoproteins. J Biochem 80:1223-1232

12. Krusius T, Finne J, Rauvala H 1976 The structural basis of the different affinities of two types of acidic N-glycosidic glycopeptides for Concanavalin A-Sepharose. FEBS Lett 71:117-120

13. Dellenback RJ, Chien S 1970 The extinction coefficient of fibrinogen from man, dog, elephant, sheep and goat at $280 \mathrm{~m} \mu$ (34792). Proc Soc Exp Biol
Med 134:353-355

14. Andrew M, Bhogal M, Karpatkin M 1981 Factors XI and XII and prekallikrein in sick and premature infants. N Engl J Med 305:1130-1133

15. Moak B, Frenzel J 1977 Antibody neutralizing material of factor VII during the first weeks of life. Eur J Pediatr 125:255-258

16. Manco-Johnson MJ, Marlar R, Hathaway, WE 1985 Neonatal protein C: Evidence for a dysfunctional protein and for the predisposition to thrombosis. Thromb Haemost 54:838(abstr)

17. Kisker CT, Robillard J, Clark WR 1981 Development of blood coagulationa fetal lamb model. Pediatr Res 15:1045-1050

18. Loly W, Israels LG, Bishop AJ, Israels ED 1971 A comparative study of adult and fetal sheep fibrinogen, sulf-fibrinogen and fibrinogen degradation products. Thromb Diath Haemorrh 26:526-540

19. Nishibe H, Takahashi N 1981 The release of carbohydrate moieties from human fibrinogen by almond glycopeptidase without alteration in fibrinogen clottability. Biochim Biophys Acta 661:274-279

20. Gilman PB, Keane P, Martinez J 1984 The role of the carbohydrate moiety in the biologic properties of fibrinogen. J Biol Chem 259:3248-3253

21. Yamaguchi $Y$, Isemura $M$, Kosakai $M$, Salo A, Suzuki M, Kan M, Yosizawa Z 1984 Characterization of fibrinectin from fetal human plasma in comparison with adult plasma fibronectin. Biochim Biophys Acta 790:53-60

22. Zhu BCR, Laine RA 1987 Developmental study of human fetal placental fibronectin: alterations in carbohydrates of tissue fibronectin during gestation. Arch Biochem Biophys 251:1-7

23. Feusner JH, Slichter SJ, Harker LA 1983 Acquired haemostatic defects in the ill newborn. Br J Haematol 53:73-84

24. Karitzky D, Kleine N, Pringsheim W, Kunzer W 1971 Fibrinogen turnover in the premature infant with and without idiopathic respiratory distress syndrome. Acta Paediatr Scand 60:465-470

25. Schmidt B, Wais U, Pringsheim W, Kunzer W 1984 Plasma elimination of antithrombin III is accelerated in term newborn infants. Eur $J$ Pediatr 141:225-227

26. Barsigian C, Gilman P, Base W, Fish S, Schaeffer A, Martinez J 1986 Catabolic properties of aglycofibrinogen synthesized by tunicamycin-treated human hepatoma (Hep G2) cells and rabbit hepatocytes. Biochim Biophys Acta 883:552-558

27. Wong K-L, Charlwood PA, Hatton MWC, Regoeczi E 1974 Studies of the metabolism of asialotransferrins: Evidence that transferrin does not undergo desialylation in vivo. Clin Sci Mol Med 16:763-774 